
cializado en Teatro. Ha sido profesor en la Universidad Nacional Autónoma de México y en varias universidades mexicanas, fue director del Centro Nacional de Investigación Teatral del Instituto Nacional de Bellas Artes, actualmente es director de la Facultad de Teatro de la Universidad Veracruzana. Es autor de los libros El director teatral intérprete-creador. Teatros y Teatralidades en México. Siglo XX y Elogio del Oximoron. Introducción a las teorias de la teatralidad. Es miembro del Sistema Nacional de Investigadores de México.

\title{
TEATRALIDAD INDIA Y COMUNITARIA EN MÉXICO. UN ACERCAMIENTO DESDE LA COMPLEJIDAD
}

\author{
DOMINGO ADAME HERNÁNDEZ
}

\section{RESUMEN}

La teoría y la práctica del teatro indio y comunitario contemporáneo de México se ha debatido entre la preservación y la transformación de los elementos culturales propios de los pueblos en los que esta actividad se realiza.

La orientación ha estado en función del origen del realizador/investigador y los resultados han sido generalmente parciales. Es por ello que, desde mi experiencia como creador/investigador de este teatro, propongo una estrategia dialógica basada en el Pensamiento Complejo que incluya y problematice todos los elementos culturales que esta teatralidad pone en juego.

\section{INDIAN AND COMMUNITY HISTRIONICS IN MEXICO: AN APPROACH FROM COMPLEXITY}

\section{ABSTRACT}

The theory and practice of contemporary Indian and community theatre in Mexico has struggled with the preservation and transformation of traditional village cultural elements where the performance is beld.

The origins of the producer/researcher bave dictated the orientation chosen with results generally turning out to be biased. It is for this reason that, in my experience as producer/researcher of this type of theatre, a dialogic strategy based on Complex Thought which includes and problematises all cultural elements this drama brings into play is proposed.

\section{INTRODUCCIÓN}

El conflicto que se ha vivido y aún persiste en México en el ámbito cultural y, específicamente en el teatral, es el enfrentamiento de concepciones muy diferentes entre el pensamiento indígena y el pensamiento occidental. El mito y la magia opuestos a la historia y a la ciencia. En el mismo sentido, la teoría y la práctica del teatro indio y comunitario con- temporáneo se debaten entre la preservación y la transformación de los elementos culturales propios de los pueblos en los que esta actividad se realiza. La alternativa, a partir de mi experiencia como creador/investigador del teatro indio y comunitario, no es la aniquilación de uno u otro componente; propongo, en cambio, una estrategia dialógica basada en el Pensamiento Complejo que incluya y cuestione todos los elementos culturales que esta 
teatralidad pone en juego, a saber: su sentido, formas de producción, intención, técnicas y conocimientos.

Considero que el teatro se debe estudiar como movimiento cultural vivo, porque verlo solamente como disciplina artística es seguir manteniendo el concepto reduccionista occidental, pues el teatro, y sobre todo la teatralidad, están presente en distintas actividades que el ser humano realiza en comunidad y, a su vez, éstas se relacionan con otras manifestaciones en la vida del individuo y de la sociedad. Por eso creo necesario identificar en cualquier investigación de carácter cultural los niveles deterministas del imprinting cognitivo y su normalización, así como sus posibilidades de debilitamiento.

Los individuos conocemos, pensamos y actuamos de conformidad con paradigmas culturalmente grabados que definen nuestras visiones del mundo, los mitos y las ideas, las actividades y las conductas. Además, un gran paradigma está profundamente inscrito en la organización de una sociedad a la cual determina, tanto como ella lo hace con él. La doctrina, sabemos, es dogmática por naturaleza, se erige como poseedora de la verdad, a diferencia de la teoría que está abierta a la crítica. Bajo el «conformismo cognitivo», nos aclara Edgar Morin, hay mucho más que eso, hay un «imprinting cultural» que marca irreversiblemente el espíritu individual en su modo de conocer y actuar ${ }^{1}$. La normalización, al controlar cualquier desviación de forma represiva o intimidatoria, se convierte en custodia del imprinting. Éste y la normalización operan recursivamente, así los modos de conocimiento de los individuos son elaborados por una cultura que produce dichos modos 2 . Precisamente por eso se pueden reconocer cambios, de tal manera que es necesario considerar, por una parte, los constreñimientos sociales, culturales e históricos que inmovilizan y aprisionan al conocimiento y, por otra, las condiciones sociales, culturales e históricas que lo movilizan o liberan posibilitando su innovación y evolución.

Para debilitar o atenuar el imprinting y la normalización, Morin visualiza tres caminos: a) una vida cultural e intelectual dialógica que admita pluralidad/diversidad de puntos de vista, intercambios múltiples de información, conflicto entre concepciones y visiones del mundo, así como la existencia de una ley del diálogo y un comportamiento individual dialógico; b) con el «calor cultural» que estimule los intercambios, enfrentamientos, y polémicas entre opiniones, ideas y concepciones; y c) con la existencia de desviantes potenciales, para lo cual, dice, se requiere un rico pluralismo cultural y cierta autonomía del

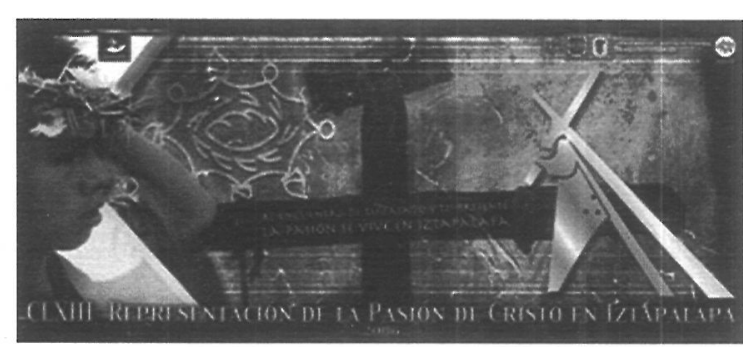

Cartel anunciador de la Pasión de Cristo. Izłapalapa 2006. estatus de los artistas, autores y pensadores.

Aplicando este aparato conceptual a nuestro tema de estudio, observamos que el discurso del teatro indio y comunitario en México ha estado marcado por el imprinting y la normalización de la Conquista, pero también ha sido confrontado por quienes buscan preservar los principios del pensamiento mesoamericano.

\section{FORMAS TRADICIONALES Y CON- TEMPORÁNEAS DE TEATRO INDIO Y COMUNITARIO}

El teatro indio y comunitario tradicional corresponde a aquel que, con un sentido de preservación cultural, practican grupos étnicos y campesinos marginados, oprimidos y dominados, localizados en rancherías, poblaciones rurales, barrios y colonias urbanas o sectores subalternos. Entre sus formas se incluyen: ceremonias, danzas-drama, danzas, comedias, farsas, sainetes, loas, églogas, autos, entremeses, pastorelas, etcétera.

Dentro de sus características están las siguientes: 1) Poseen un contenido y esencia de identidad, 2) tienen como función principal la legitimación de la cohesión grupal y 3) conservan series de complejos socioculturales, estructurados en especie de "esquemas" o «sistemas» que tienen estrecha relación tanto con la memoria histórica como con la cosmogonía y la cosmovisión; cuyas partes esenciales permanecen ocultas en la memoria colectiva y sólo reaparecen cíclicamente en las representaciones colectivas de tipo mágicoreligioso $y$, siempre, en actitud solemne ${ }^{3}$.

Como resulta evidente, el motivo religioso es predominante, efectuándose ceremonias acordes al calendario de la iglesia católica en poblaciones indígenas y mestizas, rurales y urbanas. La conmemoración de la «Semana Mayor» constituye el principal acontecimiento dentro de la iglesia católica. Las representaciones de la Pasión de Cristo tienen un carácter ritual que abarcan a la población en su totalidad con sus componentes humanos
1

Edgar Morin, «El pensamiento subyacente» en El Método IV, Las ideas, Madrid, Cátedra, 1992, pág. 29.

2

Ibidem, pág. 30

3

Manuel Jiménez Castillo, "Inves tigación sobre teatro indígena y campesino. Un punto de vista III Encuentro Nacional de Investigación Teatral, México, CITRUINBA, 1992, págs. 44-45. antropológico», en Memoria del
Teatralidad india y comunitaria en México. Un acercamiento desde la complejidad DOMINGO ADAME HERNÁNDEZ 


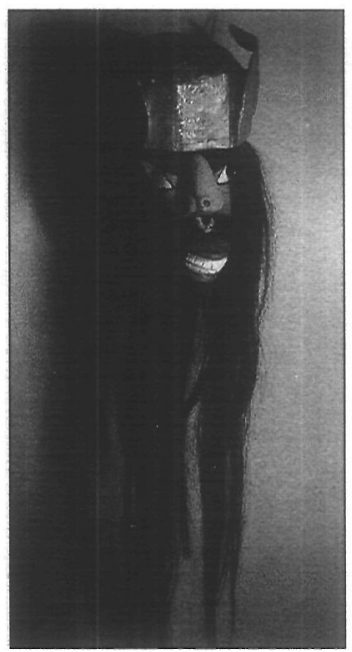

Máscara de un danzante yaqui.

Gabriel Weisz, «La piel mágica de los dioses", Memoria del Encuentro de Teatro Rural, México, Dirección General de Culturas Populares/SEP, 1985 [copia mimeográfica, sin paginación].

5

Frances Toor, A treasury of Mexican Folklore, New York, Crown, 1947, págs. 225-229.

Francisco Acosta Báez, "Teatro comunidad», La escena latinoamericana, nueva época, 5/6, págs. 52-57.

Donald Frischmann, «Etnicidad activa: nativismo, otredad y reatro indio en México», Memoria del III Encuentro Nacional de Investigación Teatral, México, $\mathrm{Cl}$ TRU-INBA, 1992, págs. 25-34.

Donald Frischmann, «El teairo en las comunidades zapatistas de Chiapas», Investigación teatral, núm. 3, págs. 13-21

Teatralidad india y comunitaria en México. Un acercamiento desde la complejidad

DOMINGO

ADAME HERNÁNDEZ y físicos. En las poblaciones indígenas se da una yuxtaposición entre el simbolismo propio y el occidental, predominando el primero en el uso del espacio, danzas, batallas, música, máscaras, vestuario, lenguaje y objetos que forman parte de la ceremonia.

Entre las culturas indias destacan las celebraciones que efectúan los Yaquis y Mayos de Sonora y Sinaloa, así como los Coras de $\mathrm{Na}$ yarit y Jalisco. Ambas son expresiones de un teatro total que engloba lo social, lo natural y lo sobrenatural.

La pastorela nació en nuestra tradición cultural decembrina como una forma de diseminación de la doctrina cristiana que, rápidamente, se convirtió en una auténtica manifestación de teatro popular.

El Teatro maya tradicional tiene diversas manifestaciones; entre otras se encuentra el Okosta Pol o «Baile de la Cabeza del Cochino», representación ritual de los mayas yucatecos; la fiesta de U k'in u k'a'ba' chan k’u -«El Cumpleaños del Niño Dios»-, de la parte oriental de la Península; y otras representaciones rituales tzotziles y tzeltales de Zinacantán, San Juan Chamula y Tenejapa.

Además de estas prácticas religiosas, existen en las poblaciones indias de México diversas manifestaciones de carácter mágico, se trata de «un fenómeno multirepresentativo donde todo se gobierna por sucesivas transformaciones» ${ }^{4}$. Es un teatro terapéutico relacionado con las formas rituales más antiguas de todas las culturas.

De igual manera, en el centro del país y en los estados de México, Guerrero, Morelos y Puebla se hacen representaciones comunitarias con tema histórico. Es conocida sobre todo la representación que se efectúa en el Peñón de los Baños en el Distrito Federal sobre La batalla del 5 de mayos.

Los carnavales constituyen otra forma de teatralidad cuyas características difieren según el contexto cultural donde se realice: indígena como en San Juan Chamula o mestizo como en Huejotzingo, Puebla.

Las representaciones contemporáneas, por otra parte, comparten en esencia las características de las tradicionales y se distinguen de ellas por la incorporación de nuevos contenidos, especialmente políticos, y de técnicas modernas que, en ocasiones, llegan a producir nuevas formas. Los temas tratados reiteradamente son aquellos que repercuten en la vida de la comunidad: alcoholismo, machismo, violencia, pérdida de valores tradicionales, cambio cultural, pandillas juve- niles, drogadicción, destrucción ecológica y emigración hacia Estados Unidos. Otra línea temática son los mitos y cuentos tradicionales. Algunos espectáculos incluyen o son exclusivamente de guiñol o marionetas. Es un teatro que va mas allá del sociodrama o del simple espectáculo de consumo para convertirse en un acontecimiento basado en la necesidad de representación de la comunidad; es un teatro hecho en los espacios y en los tiempos que la comunidad considera necesarios. No es un teatro en búsqueda de público, sino que su público es la propia comunidad que lo crea ${ }^{6}$.

Un ejemplo del teatro maya contemporáneo es el Grupo multigeneracional Sac Nicté («Flor Blanca») que existe desde 1977 en la región Puuc de Yucatán y está integrado por maestros, estudiantes, amas de casa y campesinos bajo la dirección de Carlos Armando Dzul Ek. Presentan sus obras en las fiestas de los pueblos de toda la península. Uno de sus trabajos más conocidos es el Auto de fe o choque de dos culturas. Según Donald Frischmann, los acontecimientos de este drama situado en 1562 siguen influyendo sobre el status actual de los mayas yucatecos. El tema se refiere a la imposición de la cultura española, específicamente al juicio en contra de los «idólatras y transgresores» de la religión católica orquestado por el provincial franciscano Diego de Landa ${ }^{7}$.

Otro grupo es Lo’il Maxil ( «La Risa de los Monos»), parte integral de Sna Jtz'ibajom, A. C. («La Casa del Escritor») de San Cristóbal de las Casas, integrado por trece hombres y mujeres tzotziles y tzeltales. Fue fundado en 1988 y entre las obras que ha realizado se encuentran: El burro y la mariposa (1988), Entre menos burros, más olotes (1989), El haragán y el zopilote (1989), ¿A poco bay cimarrones? (1990), Herencia fatal (1991) Dinastía de jaguares (1992), ; Vámonos al paraíso! (1993), De todos para todos (1994): "Dedicada a todos los mártires Mayas y Zoques caídos en las guerras de Chiapas». El drama explora algunas de las causas detrás del levantamiento armado de enero del mismo año, así como las preocupaciones ecológicas y mágicas en torno al último refugio del indígena despojado y marginado de la tierra propia: la selva lacandona. Otra obra es Antorchas para amanecer (1995).

En su apasionada y fecunda tarea de investigador del teatro maya, Donald Frischmann ha registrado también sus manifestaciones más recientes, las del movimiento zapatista ${ }^{8}$. 
Desde las «señas», pequeñas obras en un acto, hasta los «Consejos de ancianos», que es una resignificación de un teatro ancestral, pasando por las obras históricas. La existencia de este teatro se remonta a la época prehispánica y, en la época actual, a las primeras brigadas campesinas del Teatro Conasupo de Orientación Campesina que a fines de los setenta integró tres brigadas: una tzotzil, otra tzeltal, y otra tojolabal.

En cuanto al teatro en lengua náhuatl, el grupo Nimayana («tengo hambre») de San Miguel Tzinacapan, Cuetzalan, Puebla es un claro representante del teatro como medio de reedificación, pues nació, según uno de sus integrantes "como una necesidad de abrir aquellas bocas que estaban cerradas» en la escuela secundaria abierta, a fines de los setenta. Hicieron representaciones de las obras: El hombre nuevo y In Yankuit Tit (El fuego nuevo). En su comunidad y luego fuera de ella, descubrieron el sentido del teatro al platicar con el público; para ellos «el teatro fue muy valioso, porque nos hizo avanzar a todos los que siempre estamos situados en un rincón»". También como manifestación del teatro náhuatl actual está la que promueve en la Huasteca hidalguense Ildefonso Maya. Para él

No es la fe ni los ritos cristianos los que hacen mover a las masas para esas representaciones, sino la creencia y la fe tradicional de México que vive con sus dioses, aunque desde hace más de quinientos años hayan cambiado de nombre por la fuerza de la imposición ${ }^{10}$.

Del teatro en lengua zapoteca mencionaremos que en 1981 se integró un grupo en Juchitán a instancias del departamento de teatro indígena de la UABJO. Sus integrantes nunca habían actuado ni visto obras del teatro urbano «profesional». Por lo tanto se utilizaron máscaras para que el público no reconociera a los actores y éstos pudieran actuar con libertad. Representaron obras como Tierra y fuego sobre problemas ocurridos en 1717 , fecha en la que unos religiosos arrebataron tierras a los zapotecas de Juchitán, otra sobre el «che» Gómez (líder juchiteco en 1911) y Juchitán en el tiempo (historia de la vida social zapoteca de 1660 a 1983$)^{11}$.

El grupo Tehuantepec nació en 1987 en el istmo del mismo nombre como una necesidad comunitaria de expresar a través del teatro elementos y valores propios de su tradición, cultura y problemática social. Formó parte de la Asociación Nacional Teatro Comunidad (TECOM). Uno de sus espectáculos más significativos fue $L a$ llorona que representó a México en el Festival de Teatro Latinoamericano de Córdoba, Argentina, en 1994.

Los grupos que formaron parte de TECOM, fundada en 1987, y aquellos que aún participan en el movimiento de teatro comunitario, intentaban convertirse en monitores de su propia cultura. Su modo de producción tomó como base la «metodología de investigación-acción participativa», fundamentada en la interacción del grupo de teatro y su comunidad. Los mismos miembros

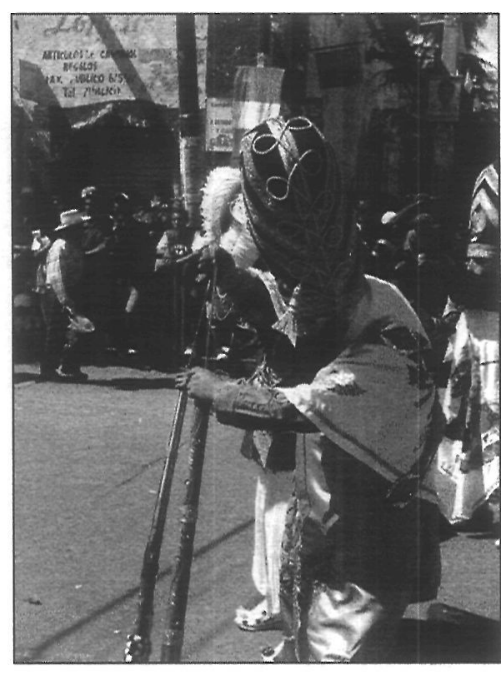

Danzante del Carnaval de Huejotzingo. de la comunidad participaban en el espectáculo, ya fuera como actores, aportando en el proceso de producción aspectos referidos al material dramático (temática, conflicto) o bien colaborando con la realización de escenografía, utilería o vestuario. De tal manera que la apropiación de la experiencia fortalecía el desarrollo de las comunidades indígenas, campesinas o urbanas populares.

Otra experiencia contemporánea es la que dio inicio en 1983 en Oxolotán, Tabasco. Se trata de un proyecto de formación, creación y difusión que, por diversos motivos, llamó la atención de propios y extraños, entre otras cosas por los altos presupuestos que manejó y por el dispendio en viajes y auto-promoción a Europa y los Estados Unidos. En 1985 el Laboratorio de teatro campesino e indígena trabajaba en siete comunidades con 1,700 alumnos y 32 maestros, o sea la escuela de teatro más grande del mundo. El proyecto, segûn una integrante del equipo directivo, se decidió mediante «consulta popular» en 20 comunidades del estado:

Fuimos a preguntarles ¿qué querían hacer en su tiempo libre? Si querían bailar, cantar, tocar la guitarra...lo que ellos quisieran nosotros íbamos a llevarles. Entonces, de estas 20 comunidades destacó Oxolotán que con una investigación de, digamos el $80 \%$ de su población, el 75 contestó que quería hacer teatro (sic) ${ }^{12}$.

\section{Un reportaje de 1991 consignaba:}

Con el apoyo irrestricto de la escritora Julieta Campos, entonces presidenta del DIF (Desarrollo Integral de la Familia) de la entidad nació el Laboratorio de Teatro Campesino e Indígena de Tabasco [...].
9 Moisés Castro Payno, Eulalia Chávez Tomás, Blas Soto Islas, et al., "El teatro de San Miguel Tzinacapan no ha muerto, vive en las organizaciones", Memoria del Encuentro en torno al teatro rural. México, Teatro Rural/Dirección General de Culturas Populares/SEP, 1985 [copia mimeográfica, sin paginación].

10

Ildefonso Maya, "El teatro masivo indígena, base del teatro mexicano» en Memoria del III Encuentro de Investigación Teatral, México, CITRU-INBA, 1992 págs. 15-24.

11 Macario Małus, "Teatro en lengua zapoteca», Memoria del Encuentro en torno al teatro rural. México, Teatro Rural/ Dirección General de Culturas Populares/SEP, 1985 [copia mimeográfica, sin paginación].

12

Lourdes Arriaga y Santos Pisté Canche en Memoria del Encuentro en torno al teatro rural, México,Teatro Rural/Dirección General de Culturas Populares/ SEP, 1985 [copia mimeográfica, sin paginación].

Teatralidad india y comunitaria en México. Un acercamiento desde la complejidad

DOMINGO

ADAME HERNÁNDEZ 


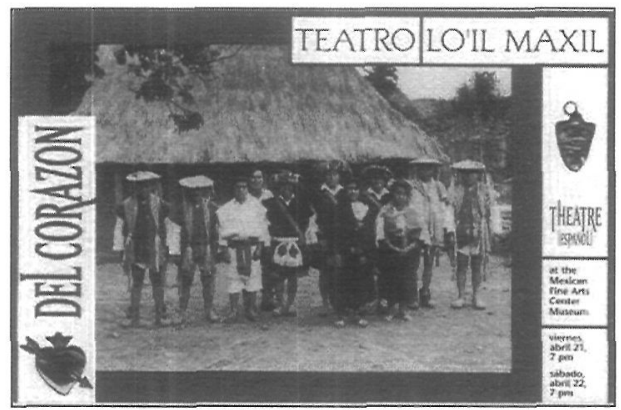

Cartel anunciador grupo Lo'il Maxil.

13

Magdalena Molina, "Teatro campesino e indígena. El despertar del jaguar», Memoria de Papel, núm.1, CNCA, México, pág. 103.
Teatralidad india y comunitaria en México. Un acercamiento desde la complejidad DOMINGO ADAME HERNÁNDEZ
Seis años después, en 1989 el LTCI contaba ya con una primera generación de ciento veintitrés maestros de teatro y tres mil alumnos formados con la técnica Stanislawski, la biomecánica -enseñanza simultánea de ritmos diferentes para liberar la expresión corporal-, y un programa de 31 materias más. En este lapso se conformó un repertorio de 43 obras teatrales, que incluyó una creación colectiva de los integrantes del laboratorio: La tragedia del jaguar, así como obras de autores nacionales contemporáneos, y piezas universales como Bodas de sangre de Federico García Lorca ${ }^{13}$.

Frente a esto, es legítima la pregunta sobre el carácter campesino y/o indígena del proyecto, pues lo que predomina es el teatro occidental. Para lo que sin duda sirvió fue para difundir -una vez más- en el extranjero y ante los propios connacionales la imagen folklórica de México, es decir, fortaleció la normalización del imprinting cultural autoritario, manipulador y populista de los gobiernos emanados de la Revolución. Es evidente que los llamados «Laboratorios de Teatro Campesino e Indígena» siguieron pautas de creación y producción ajenas al contexto propio y que constituyeron iniciativas gubernamentales para manipular y postergar el genuino avance comunitario.

\section{VARIABLES DEL TEATRO INDIO Y COMUNITARIO EN MÉXICO}

En un afán por sintetizar las distintas formas de esta teatralidad, enumero las siguientes variables:

1. Teatro hecho por miembros de una comunidad, en la comunidad y para la propia comunidad. Se trata, sobre todo, del teatro ritual en el cual no hay distinción entre actores y espectadores.

2. Teatro hecho por miembros de una comunidad, en la comunidad y para distintas comunidades, por ejemplo el teatro religioso como $\mathrm{La}$ pasión de Cristo que en los últimos años ha adquirido carácter comercial. Esto genera en el público el interés de hacer su propia «Pasión»y, en consecuencia, se establece un espíritu de competencia. En el lado opuesto están los grupos de Teatro-Comunidad surgidos en los últimos años donde se establece un tipo de intercambio entre grupos; el público, aunque distinto, tiene rasgos comunes, la agrupación no resulta del todo ajena.

3. Teatro hecho por miembros de una o varias comunidades, fuera de la comunidad y para distintas comunidades. Es el caso del teatro patrocinado por instituciones de gobierno, religiosas o políticas que capacitan a personas de comunidades indígenas y campesinas para hacer un teatro de carácter didáctico.

4. Teatro hecho por personas ajenas a las comunidades, en la comunidad y para presentarse en varias comunidades. Se trata de grupos formados por jóvenes provenientes de centros urbanos que llegan a comunidades indígenas con el propósito de integrarse a ellas, de vivir de acuerdo a sus costumbres las cuales «recrean artísticamente» para resaltar sus tradiciones.

5. Teatro hecho por personas de la comunidad, en la comunidad y para distintas comunidades, pero con intereses distintos a los de la comunidad. Es el caso del teatro patrocinado por instituciones de gobierno, religiosas o políticas que realizan trabajos o se presentan en comunidades indígenas o campesinas sin reflejar el proyecto o las condiciones de las propias comunidades. Por ejemplo, el Teatro Campesino e Indígena de Tabasco.

\section{SENTIDO DEL TEATRO INDIO Y CO- MUNITARIO}

Considero que cualquier intento por acercarse al teatro indio y comunitario debe tener en cuenta el sentido que para las propias comunidades tienen las representaciones. Menciono, en seguida, dos señalamientos producto de la práctica y la investigación directa.

German Meyer, investigador, creador y participante activo del movimiento del Nuevo Teatro Popular en México entre 1976 y 1986, considera que más que un espectáculo en sí, en el cual se abre [un] «espacio vacío» que un autor, un director y unos actores van a tratar de llenar para un espectador que viene a «mirarse». Podemos vislumbrar desde un principio el teatro indio como un campo «lleno» de fuerza, que recibe su energía de 
muchos polos y la redistribuye a muchos otros. Nada más extraño a una concepción del teatro indígena, dice

...que la noción de un teatro en la que se encierra uno para enterarse de lo que a alguien se le ha ocurrido manifestarnos. Aquí todo está arreglado: los polos que producen la energía pueden ser tanto el calendario como la tradición, el mayordomo, la manda, el placer del juego o de la necesidad; algunos de los polos que se benefician con esta energía podrían ser la cohesión social, las buenas relaciones con los dioses, la integración de una personalidad y de una identidad. Más que un «espacio vacío», se entiende entonces que este teatro necesita de un «espacio lleno» de simbología, de valores sociales, de tradiciones artísticas. Y este [espacio] lo ofrecen no solamente los actores que son del mismo pueblo o de la misma cultura, no solamente las obras que son las mismas año tras año, no solamente la puesta en escena o la coreografía que se transmite por tradición y no se inventa en cada función, sino también, y sobre todo un «espacio lleno» de la seguridad de un sentimiento o de la confirmación de una visión del mundo. El teatro deja de ser entonces un producto que se consume o no: es el espejo de un rostro inalterable ${ }^{14}$.

\section{Por su parte, Donald Frischmann indica:}

En el teatro comunidad actores rituales emplean coreografía, música y cantos, máscaras, vestuarios y objetos rituales. Todo movimiento, palabra, motivo y color ha sido cuidadosamente seleccionado y elaborado para elaborar los fines mágicos deseados. El objetivo primordial de los participantes es entrar en comunicación con las fuerzas del cosmos, asumiendo así el papel de mensajero y abogado de la comunidad ante las fuerzas mayores. Cuando la comunidad entera asiste a tales representaciones es en calidad de coadjutor y no como espectador, ya que los destinatarios intencionados son las deidades mismas. Por lo tanto, la estética que se persigue en las representaciones ritualísticas responde a motivaciones cosmogónicas y es traducida por los ejecutantes en aquellos elementos visuales y sonoros que mejor puedan complacer al destinatario sobrenatural y así lograr los fines deseados. Tales manifestaciones culturales, rituales y estéticas surgen del «México profundo» que para Bonfil Batalla está constituido por una gran diversidad de pueblos cuya manera de entender el mundo y organizar la vida tiene su origen en la civilización mesoamericana prehispánica. En este contexto se inserta el teatro comunidad que es una experiencia escénica y de promoción comunitaria en la que se crea o recrea manifestaciones dramáticas y representacionales, por y/o para los miembros de comunidades indígenas, campesinas o urbano-populares ${ }^{15}$.

\section{EL CONCEPTO «COMUNIDAD» DESDE UNA PERSPECTIVA COMPLEJA}

Entiendo por comunidad la agrupación de individuos que comparten aspectos culturales fundamentales de tipo social, religioso y estético. En cuanto a lo social podemos mencionar comunidades lingüísticas, geo-políticas, económicas, políticas, profesionales, sexuales, educativas, etcétera. Al respecto de lo religioso habría que considerar a las diversas religiones $\mathrm{y}$ a todas las sociedades culturales; por último, en lo que se refiere a lo estético, habría que incluir a las comunidades artísticas, de intelectuales y de artesanos, por citar algunas. Si bien en todos los casos existe un elemento común que les otorga el carácter de «comunidad», el resto de los elementos «culturales» de los individuos que la forman son, casi siempre, diferentes. Unidad y diversidad es el binomio que identifica a la comunidad. Habría que preguntar cuál es el elemento que permite la cohesión, pues, sin duda, el mayor problema es cómo hacer que exista verdadera unidad más allá de las diferencias. Este elemento indispensable es la ética que consiste en la valoración del ethos, del ser, de los derechos de la persona a una vida con dignidad. La ética, además de ser un elemento cohesionador de cada comunidad, permite la convivencia entre las distintas comunidades. De este modo podemos decir que una comunidad es aquella cuyos miembros comparten una ética. O dicho de otra manera, la ética comunitaria es la que permite la interacción de los individuos al interior de su comunidad y fuera de ella -en otras comunidades- es decir en el mundo ${ }^{16}$.

No tener sentido de comunidad es vivir defendiendo sólo una visión de la realidad y rechazando otras diferentes; es propiciar los nacionalismos, los fascismos, las intolerancias, los racismos y las discriminaciones. Por el contrario, tener un sentido de comunidad es reconocer la multiculturalidad, ser tolerante y respetuoso de las diferencias sin anteponer $y$, menos aún, querer imponer el punto de vista propio a otras comunidades. Lo primero es ignorancia, lo segundo exige conocimiento y amor hacia lo humano y a todo lo que existe. Podría decirse que estamos hablando de una comunidad ideal y, por lo tanto, inexistente. No es así, en todo caso lo que señalamos son las metas a las que toda comunidad puede aspirar. Reconocemos, pues, que existen di-
14

German Meyer, «El teatro en las fiestas indígenas», Memoria del Encuentro Nacional en torno al Teatro Indígena y Campesino, Teatro rural/Dirección General de Culturas Populares/SEP, México, 1985 [copia mimeográfica, sin paginación].

15

Donald Frischmann, «El teatro de comunidad en México: teoría y praxis», en Entorno, nuevo época, núms. 56-57, págs. 3643.

16

La definición del compromiso ético de Bach y Darder cierran perfectamente el círculo de lo aquí expresado: "saber que lo que hago y cómo lo hago tendrá una repercusión sobre mí mismo, sobre el otro y sobre el entorno y por tanto lo tengo en cuenta, lo pienso y actúo procurando que esta repercusión sea lo más positiva posible...no disfrazo la realidad a mi conveniencia, ni me instalo en el inmovilismo». Eva Bach y Pere Darder, Desedúcate. Una propuesta para vivir y convivir mejor, Paidos, México, 2005, pág. 76.

Teatralidad india y comunitaria en México. Un acercamiento desde la complejidad

DOMINGO

ADAME HERNÁNDEZ 


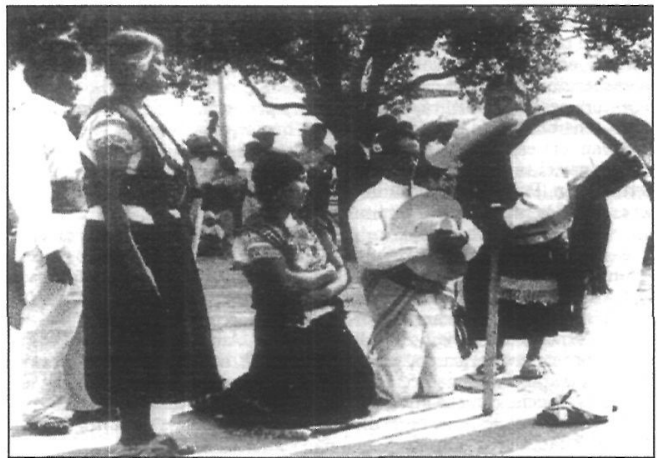

Brigada Xicotencail (Tlaxcala). versas etapas para llegar a alcanzarlas, pero lo que no puede perder de vista cada miembro de la comunidad es la actitud ética. Sin ella sería imposible impulsar un movimiento de teatro comunitario, pues para que éste exista debe surgir de las convicciones más auténticas de las mujeres y los hombres que buscan expresar, creativa y sensiblemente, su pertenencia a una comunidad y su deseo de convivir y compartir experiencias con otras diferentes a ella.

Es necesario, por lo tanto: a) Contar con una concepción amplia del concepto «comunidad» que dé cabida a todos aquellos grupos e individuos que, sin importar sus condiciones geográficas, étnicas, políticas, sexuales, etcéte$\mathrm{ra}$, deseen expresar un sentir comunitario; b) Aspirar a la formación de la persona comunitaria: tolerante y respetuosa de las diferencias y, sobre todo, respetuosa de la vida humana y de la naturaleza; c) Estimular la pluralidad en la creación sin imponer a ninguna comunidad el teatro que se considere que es el más conveniente para ella.

El teatro comunitario fortalece al individuo en una nueva relación consigo mismo, con su comunidad y con los otros. Un teatro que logre integrar a su público en una unidad derivada de sus orígenes será el teatro imprescindible para lograr los ideales de la democracia incluyente.

\section{EL CONCEPTO «TEATRO» EN UNA PERSPECTIVA COMPLEJA}

Todos los grandes momentos del teatro universal en oriente y occidente han surgido de un vínculo estrecho entre las dimensiones ética, estética y religiosa de lo humano. El teatro ha sido siempre un medio para confrontar la realidad del hombre, para lo cual se requiere disposición para enfrentar las coacciones que lo oprimen. Lo que resulta de ello es una mejor comprensión de la realidad y una redimensión de la complejidad del hombre. Por ello el teatro es, ante todo, una forma de conocimiento. Conocimiento de las fuerzas que mueven al mundo y de las relaciones del hombre consigo mismo y con los demás.

La sociedad contemporánea parecería no estar muy interesada en este tipo de experiencias a través del teatro. El afán por obte- ner satisfacciones inmediatas ha empobrecido considerablemente a nuestra sociedad. ¿En dónde puede encontrarse entonces una fuente que alimente al teatro de nuestro tiempo y del porvenir? La respuesta surge de manera inmediata: en la tradición y en las preguntas fundamentales que el hombre puede hacerse sobre su existencia. Intentaremos enseguida explicar estas dos ideas.

Considerar a la tradición como fuente del nuevo teatro no significa remontarse al pasado con un sentimiento de nostalgia y querer revivir en el presente lo que ya fue. Significa reconocernos como parte de un proceso cultural que no comenzó con nuestra propia persona, sino que se ha conformado con las aportaciones de múltiples generaciones y del cual, queramos o no, somos continuadores. El reto, entonces, es actualizar permanentemente la tradición, ser conscientes de ella para no repetirla de modo inútil, o romperla o cancelarla sin darnos cuenta, pues cualquiera de estas actitudes significaría reducir una parte fundamental de nuestra condición humana.

Referirse a la «tradición» requiere de otra precisión: es más conveniente hablar de «tradiciones». Es evidente que si bien la condición humana es una sola, el hombre forma parte de muy diversas prácticas entre ellas las teatrales. En México, hemos dicho, las tradiciones culturales y teatrales distan mucho de ser homogéneas y su relación está claramente diferenciada desde una perspectiva ideológica. Entonces, surge otro problema. ¿A qué tradición se debe o se puede uno ligar? En términos generales, a aquella que sea capaz de superar las diferencias superficiales entre los hombres para ir a las coincidencias más profundas. Esta especie de depuración ideológica y teatral requiere ante todo del conocimiento. En nuestros días, una mujer o un hombre que se dedique al teatro no pueden permanecer ajenos al mundo que lo rodea. La falta de información y de reflexión limita el campo de la visión y conduce a otorgar validez sólo a lo que tenemos frente a nosotros. El acceso a la información que genere la reflexión y la creación requiere, sin embargo, de un primer paso fundamental: la decisión de comprometerse vitalmente con el teatro, y esto no quiere decir ni hacer del teatro un medio de subsistencia como cualquier otro, ni entregarse a él románticamente sin esperar recompensa alguna. Comprometerse vitalmente con el teatro significa-desde mi punto de vista- que puedo entender la difícil y amplia tarea que entraña la creación teatral; que puedo comprender su 
enorme significación social; que sé que puedo serle útil asumiendo, con generosidad y entusiasmo alguna de las tantas funciones de que se compone; que puedo contribuir para que otros como yo encuentren en el teatro algunas respuestas a sus interrogantes y también, por supuesto, para que logren una experiencia placentera que, por serlo, permanecerá y será siempre productiva. Se trata, como puede verse, de una cuestión ética y estética que exige un mayor compromiso con lo humano.

\section{PROPUESTA ECOPOIÉTICA}

Para concretizar las reflexiones anteriores es necesario considerar aspectos teórico-metodológicos provenientes de la epistemología de la complejidad, a fin de establecer relaciones pertinentes entre diversos conocimientos que den cuenta del fenómeno en su conjunto. Propongo, por lo tanto, una estrategia transdisciplinaria y "ecopoiética» apta para integrar dinámicamente la multiplicidad de expresiones representacionales de una sociedad pluricultural como la mexicana y, a éstas, con otras del mundo.

Uno de los mayores obstáculos al que nos enfrentamos los investigadores es el de la atomización de los saberes, por eso la transdisciplinariedad es una alternativa pertinente, ya que hace emerger de la confrontación de las disciplinas nuevos datos que las articulan y nos ofrecen una nueva visión de la naturaleza y de la sociedad. Además, dentro del conocimiento académico, es común que se subestimen las implicaciones corporales y cognoscitivas de lo que implica este cambio epistémico y cosmogónico hacia el pensamiento complejo y la transdisciplina. Distintas formas de sabiduría perenne y tradicional han practicado desde hace milenios un desarrollo de saberes locales y universales sobre la base de la ruptura de la dualidad sujeto-objeto. La investigación tradicional practicada por los pueblos aborígenes ha generado saberes de infinita complejidad. Dicha investigación tradicional se forja desde una corporeización de la experiencia cognoscitiva, desde un cuerpo que siente, que vibra y ama. Se trata de una articulación de vivencias y saberes, donde se gesta el conocimiento complejo, trascendente y planetarizado; un saber holográfico sagrado. Así, la ruptura de la dualidad es posible a través de la corporeización de la experiencia cognoscitiva.

La ecologización del pensamiento nos lanza hacia la inaplazable necesidad de cor- poreizar y emocionear el conocimiento (incorporar el cuerpo y las emociones al acto de saber: entrar en un conocimiento somático). Para ello nos parece indispensable acercarnos nuevamente al mito y al rito, no desde una nueva racionalización, lo cual constituiría una necedad reiterativa de regreso a nuestros viejos vicios, sino desde el Ser-Cuerpo que es el espacio privilegiado, el hogar de la mitopoiesis. La crianza de habilidades cognoscitivas-emocionales mediante un elaborado escenario de rituales y mitos permite el cruce de sensaciones, donde los olores, el tacto, los sonidos, la vista y el gusto son contrastados dentro de una compleja cosmogonía. El acto ritual es concebido como el espacio donde el mito integra compleja y holográficamente la infinita trama de las relaciones personalescomunitarias-planetarias.

Mi propuesta se encamina precisamente en este sentido: coadyuvar a la creación de espacios de transformación y de empoderamiento personal, de recomunalización o comarcación, a través de la puesta en práctica de procesos eco-poiético-rituales, los cuales se articulan con procesos de creatividad comunitaria orientados a la transformación social. Esta opción se construye retomando y recreando particularmente la cosmogonía de nuestros antiguos pueblos mesoamericanos y estableciendo un diálogo entre las diversas sabidurías de los pueblos milenarios, los saberes locales tradicionales y la ciencia ecologizada y sacralizada. Afirmo desde mi experiencia de comarcación y co-construcción de alternativas al desarrollo, que estos espacios y praxis eco-poiético-rituales permiten abordar de forma creativa y exitosa problemas centrales de la convivencia social, tales como el poder, la feminidad-masculinidad, la generación de saberes locales, los conflictos, los procesos de cambio, la creatividad, la violencia, etcétera. El reencuentro con la experiencia de lo sagrado -lo cual se vive en los rituales no secularizados- es central en la generación de los procesos de transformación y de comarcación. El contacto con lo sagrado nos permite trascender el sentido de separatividad y acceder a lo «numinoso», es decir a la profundidad de la experiencia vital, de la relación con la naturaleza, con nosotros mismos y con nuestro entorno. Es lo que permite reintegrar la dimensión espiritual del ser humano, al mismo tiempo que lleva a reajustarnos a los patrones de la naturaleza y a restituir el ritmo hacia nosotros mismos, hacia el entorno y hacia el cosmos y, de esta
Teatralidad india y comunitaria en México. Un acercaniento desde la complejidad DOMINGO ADAME HERNÁNDEZ 
manera, re-crear un pulso y un ritmo comunitario hacia un mundo posible: la utopía holográfica y sagrada de una Transformación Social Espiritual.

Confío que al establecer un diálogo complejo, transdisciplinario y ecopoietico entre teatralidades tradicionales y contemporáneas, sagradas y profanas, prosaicas y poéticas, dogmáticas y liberadoras será posible reconocer las matrices culturales que son fuente inagotable de creación, desde donde puede emerger la autonomía espiritual de cada persona.

\section{BIBLIOGRAFÍA}

Acosta Báez, Francisco, «Teatro comunidad», La escena latinoamericana, nueva época, $5 / 6$, págs. $52-57$.

Arriaga Lourdes y Santos Pisté Canche, «EI laboratorio de teatro campesino e indígena de Tabasco», en Memoria del Encuentro en torno al teatro rural. México,Teatro Rural/Dirección General de Culturas Populares/SEP, 1985 [copia mimeográfica, sin paginación].

Bach, Eva y Pere Darder, Desedúcate. Una propuesta para vivir y convivir mejor, México, Paidós, 2005.

Castro Payno, Moisés, Eulalia Chávez Tomás, Blas Soto Islas, et al., «El teatro de San Miguel Tzinacapan no ha muerto, vive en las organizaciones», Memoria del Encuentro en torno al teatro rural. México, Teatro Rural/Dirección General de Culturas Populares/SEP, 1985 [copia mimeográfica, sin paginación].

Frischmann, Donald, «El teatro de comunidad en México: teoría y praxis», en Entorno, nueva época, núms. 56-57, págs. 36-43.

- , «El teatro en las comunidades zapatistas de Chiapas», Investigación teatral, núm. 3, págs. 13-21.
-, «Etnicidad activa: nativismo, otredad y teatro indio en México", Memoria del III Encuentro Nacional de Investigación Teatral, México, CITRU-INBA, 1992, págs. 25-34.

Jiménez Castillo, Manuel, «Investigación sobre teatro indígena y campesino. Un punto de vista antropológico», en Memoria del III Encuentro Nacional de Investigación Teatral, México, CITRU-INBA, 1992, págs. 42-52.

Matus, Macario «Teatro en lengua zapoteca», Memoria del Encuentro en torno al teatro rural. México, Teatro Rural/ Dirección General de Culturas Populares/SEP, 1985 [copia mimeográfica, sin paginación].

Maya, Ildefonso «El teatro masivo indígena, base del teatro mexicano» en Memoria del III Encuentro de Investigación Teatral, 1992, México, CITRU-INBA.

Meyer, German, «El teatro en las fiestas indígenas", Memoria del Encuentro Nacional en torno al Teatro Indígena y Campesino, Teatro rural/Dirección General de Culturas Populares/SEP, México, 1985 [copia mimeográfica, sin paginación].

Molina, Magdalena, «Teatro campesino e indígena. El despertar del jaguar», Memoria de Papel, núm. 1, CNCA, México, pág. 103.

Morin, Edgar, «El pensamiento subyacente» en El Método IV, Las ideas, Madrid, Cátedra, 1992.

Toor, Frances, A treasury of Mexican Folklore, New York, Crown, 1947.

Weisz, Gabriel, «La piel mágica de los dioses», Memoria del Encuentro de Teatro Rural, México, Dirección General de Culturas Populares/SEP, 1985 [copia mimeográfica, sin paginación].
Teatralidad india y comunitaria en México. Un acercamiento desde la complejidad

DOMINGO

ADAME HERNÁNDEZ 